\title{
Numerical and experimental study on the flow characteristics and the erosive ability of magnetorheological jet
}

Zhe Lv ( $\sim$ Izjslyz@126.com )

Shandong University of Technology https://orcid.org/0000-0001-7487-2168

Rongguo Hou

Ping Lu

Xiangtian Wang

\section{Research Article}

Keywords: Particles laden flow, abrasive waterjet, flow field, abrasive erosion

Posted Date: April 21st, 2021

DOI: https://doi.org/10.21203/rs.3.rs-437473/v1

License: (c) (1) This work is licensed under a Creative Commons Attribution 4.0 International License. Read Full License

Version of Record: A version of this preprint was published at The International Journal of Advanced Manufacturing Technology on July 13th, 2021. See the published version at https://doi.org/10.1007/s00170-021-07647-6. 


\title{
Numerical and experimental study on the flow characteristics and the erosive ability of magnetorheological jet
}

\author{
Zhe Lv", Rongguo Hou, Ping Lu, Xiangtian Wang \\ School of Mechanical Engineering, Shandong University of Technology, Zibo, China, \\ 255000
}

\begin{abstract}
Fluid jet machining has been widely used in machining of hard-brittle materials. However, the diffusion of jet flow significantly affects the erosion capacity. Magnetorheological fluid has been considered to take the role of pure water for carrying abrasive particles, due to its better concentration when the external magnetic field is applied. The present investigation focuses on the flow characteristics of magnetorheological jet, which are involved in the basic aspects of erosion mechanism. Numerical models of excitation coil and jet flow field were established to investigate the fluid pressure distribution on the target surface and the trajectories of laden particles. Experiments were also conducted to verify the simulation results and evaluate the feasibility of MR jet on surface finishing. The results indicated that the utilization of high magnetic intensity can effectively improve the concentration of jet flow and the processing quality of workpiece surface.
\end{abstract}

\section{Keywords}

Particles laden flow; abrasive waterjet; flow field; abrasive erosion

\section{Introduction}

The urgent demand of high-precision components used in electronics, optics and aerospace equipments calls for effective and damage-free processing methods in recent years. Plenty of these components are made of hard-brittle materials which are not suitable for traditional mechanical machining such as milling and grinding. Fluid jet carrying hard abrasives has been utilized for processing ceramics, quartz and silicon wafers owing to its low thermal effect and high flexibility [1, 2]. Chen et al. [3]

${ }^{*}$ Corresponding author. Tel/Fax: +86 533 2786910. E-mail address: lzjslyz@126.com (Zhe Lv). 
utilized low-pressure abrasive flow in microgroove machining and numerically modeled the trajectory and erosion action of particles. The results show that the channels with fine surface can be fabricated. Liu et al. [4] attempted to use abrasive waterjet on the turning of alumina ceramics. The material removal was mainly attributed to micro-chipping rather than cracking. Kowsari et al. [5] investigated the effects of viscosity and concentration on the shape of holes drilled on glass by abrasive slurry jet. The results demonstrated that the use of high-molecular-weight solution can significantly decrease the damages on the edges of holes. Due to the high pressure gradient at the interface between jet flow and ambient air, the outer boundary of jet flow is involved with strong air entrainment and high turbulence [6]. Therefore, the diameter of jet at a certain distance from the nozzle outlet will significantly increase. The diffusion of fluid jet is unfavorable for the deterministic finishing and shaping of complex surfaces.

Magnetorheological fluid has a viscosity-controllable characteristic and has been utilized in the finishing of components. When applied on external magnetic field, micro iron carbonyl powders dispersed in insulating base fluid will change into well-aligned chains and the viscosity of the magnetorheological fluid will significantly increase. The stable suspension formed in magnetic field can be mixed with hard abrasive particles for polishing with considerable removal efficiency and quality[7]. Khatri et al. [8] implied magnetorheological finishing on silicon mirrors and used molecular dynamics simulation on the process. The experimental and simulation results indicated that the final surface roughness was $6.4 \mathrm{~nm}$ and the removal was atomic-scale. Saraswathamma et al. [9] investigated the effect of working gap on finishing performance of ball end magnetorheological process on the silicon wafer. The results demonstrated that the reduction in surface roughness was up to $58 \%$. Sidpara and Jain [10] investigated the force exerted on curved surface in magnetorheological finishing. The results indicated that normal and tangential forces had close relation with the interaction between the fluid and the surface.

Considering the controllable viscosity and high flexibility of magnetorheological fluid, some researchers have utilized magnetorheological jet of abrasive mixture in high precision machining of optical components with complex shapes. With the aid of external magnetic field, stabilized round jet can be formed at an appropriate distance outside the nozzle to adapt the surface shape. Tricard et al. [11] utilized magnetorheological jet mixed with hard particles to polish optics. The results indicated that the magnetically stabilized jet was suitable for precision finishing of complex shapes. Kim et al. [12] investigated the removal process in magnetorheological jet polishing of BK7 glass specimen and found that mirco-cutting and ploughing were the dominating failure mechanisms. The surface finished by the jet has a surface roughness of RMS $1.3 \mathrm{~nm}$ and $30 \mathrm{~nm}$ Rp-v. The previous studies mainly concerned about the improvement of material removal and the processing performance. However, the flow behavior of MR jet behind the improved machining results has not been given sufficient attention.

In present study, numerical models were established to investigate the flow characteristics of MR jet under external magnetic field. The influence of magnetic 
intensity on the jet flow concentration and particle motion has been analyzed. Erosion tests using MR jet was conducted to verify the computational results. Finishing experiments were also implemented to assess the feasibility of MR jet for damage-free surface processing.

\section{Modeling}

The magnetorheological jet with high viscosity is formed under the external magnetic field which is generated by a coil carrying current. The electromagnetic field involved can be described by Maxwell's equations [13]:

$\nabla \cdot B=0$

$\nabla \times E=-\frac{\partial B}{\partial t}$

$\nabla \cdot D=q$

$$
\nabla \times H=J+\frac{\partial D}{\partial t}
$$

Where $B$ and $E$ are the magnetic and electric fields, respectively, and $H$ and $D$ are the induction fields for the magnetic and electric fields, respectively. $q$ is the electric charge density, and $J$ is the electric current density vector.

The induction fields $H$ and $D$ are defined as:

$H=\frac{1}{\mu} B$

$D=\varepsilon E$

Where $\mu$ and $\varepsilon$ are the magnetic permeability and the electric permittivity, respectively. For sufficiently conducting media such as liquid metals, the electric charge density $q$ and the displacement current are customarily neglected.

The current density is given by Ohm's law as:

$$
J=\sigma(E+U \times B)
$$

From Ohm's law and Maxwell's equations, the induction equation can be derived as:

$$
\frac{\partial B}{\partial t}+(U \cdot \nabla) B=\frac{1}{\mu \sigma} \nabla^{2} B+(B \cdot \nabla) U
$$

The geometric model of the computational domain of electromagnetic field established in ANSYS is shown in Fig.1. The excitation coil is modeled as a hollow cylinder. The MR jet focusing tube was located at the centerline of the coil. Both the coil and the tube were surrounded by the air medium. The material of coil and focusing tube was copper and stainless steel, respectively. The relative permeability of copper was set as 1 , and the B-H curve of stainless steel was assigned. The coil and the focusing tube were modeled by using SOLID97 element. SOLID97 is defined by 
eight nodes and has up to five degrees of freedom per node out of six defined DOFs. The element has nonlinear magnetic capability for modeling B-H curves or permanent magnet demagnetization curves. The turn of the coil was 2000 and the section area of the coil was assigned as $0.0016 \mathrm{~m}^{2}$. The current density was ranged within 0-1.5 A. Magnetic flux parallel boundary was assigned on the tube surface. The boundary of the air medium was modeled using INFIN111 element for approximating the far field.

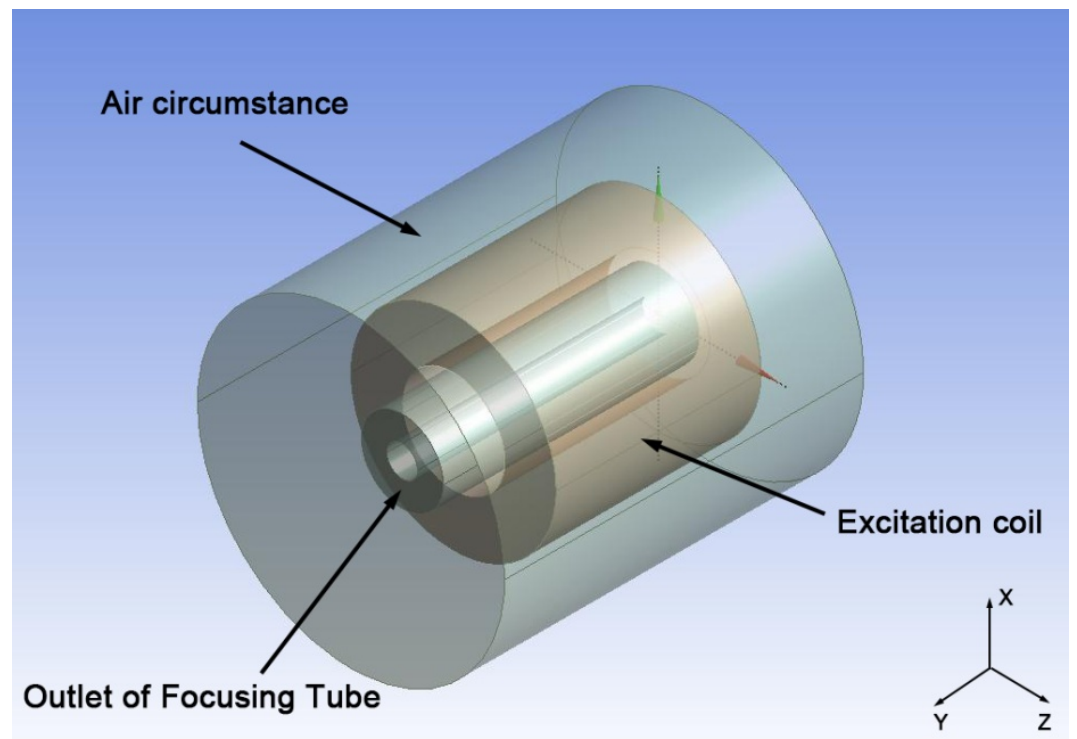

Fig.1. Computational domain of the electromagnetic field.

The geometric model of MR jet flow field established in FLUENT is shown in Fig.2. Focusing tube was located at the upper region. The outlet of nozzle was assigned as pressure inlet boundary condition, and the pressure value was $20 \mathrm{MPa}$. The inner surface of focusing tube was assigned as wall boundary. The outer boundary of air was assigned as pressure outlet with an atmosphere pressure. Workpiece surface was located at the bottom of the flow field with a standoff distance of $25 \mathrm{~mm}$ and assigned as wall boundary. The external magnetic field was applied on the jet flow at the upper region, and the distribution of magnetic flux was imported from the data file of electromagnetic analysis. The fluid phase was modeled as $5 \mathrm{wt} \%$ hydroxyl iron power water solution. The relative magnetic permeability of the fluid is 3.2. Discrete phase model was used to track the silicon carbide abrasive particle movement in fluid. The interaction between the particles is ignored. The mass flow rate of abrasive is $1 \mathrm{~g} / \mathrm{s}$, and the diameter of single particle is $15 \mu \mathrm{m}$. With the knowledge of the induced electric current, the magnetohydrodynamics coupling is achieved by introducing additional source terms to the fluid momentum equation and energy equation. For the fluid momentum equation, the additional source term is the Lorentz force given by:

$F=J \times B$

The coupled MHD equations of jet flow with the applied magnetic field were solved by using magnetic induction method. The computational domain was meshed with hexahedral elements. An evaluation on the independency of computational accuracy on mesh density was performed before further simulations, and the model was finally 
meshed with 245144 elements.

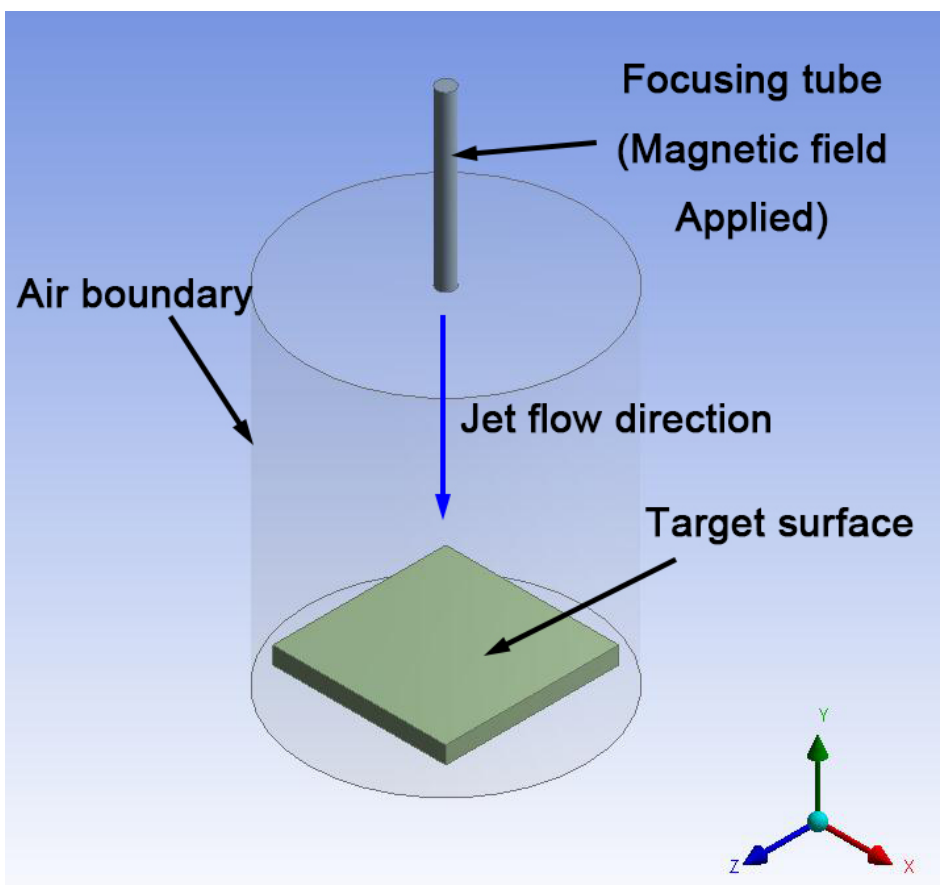

Fig.2. Geometric model of the jet flow field.

\section{Simulation results and discussions}

The concentration of MR jet flow is depended on the distribution and the intensity of the external magnetic field. The magnetic flux density distribution nearby the focusing tube under different excitation current of the coil is shown in Fig.3. The magnetic induction concentrates at the periphery of the focusing tube. The distribution pattern is relatively stable under different current intensities. It can be found that the magnitude of the magnetic flux density increases with an increment of excitation current. 


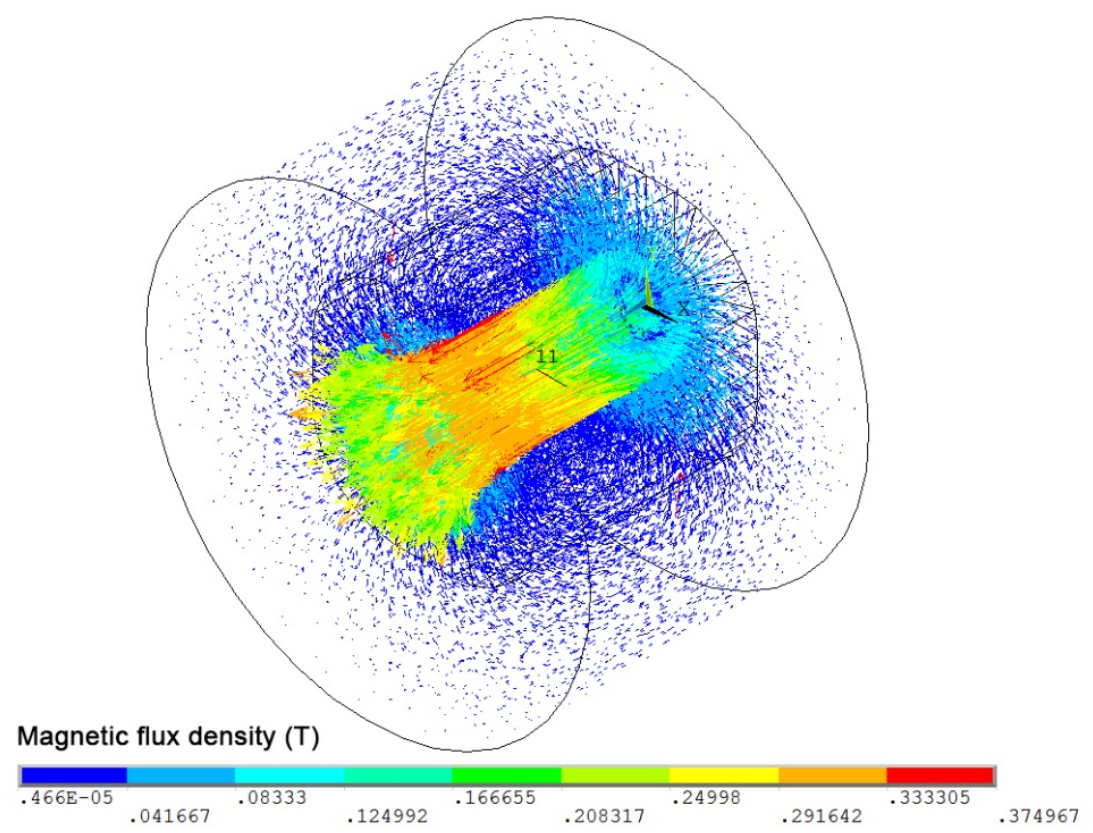

(a) Current $=0.5 \mathrm{~A}$.

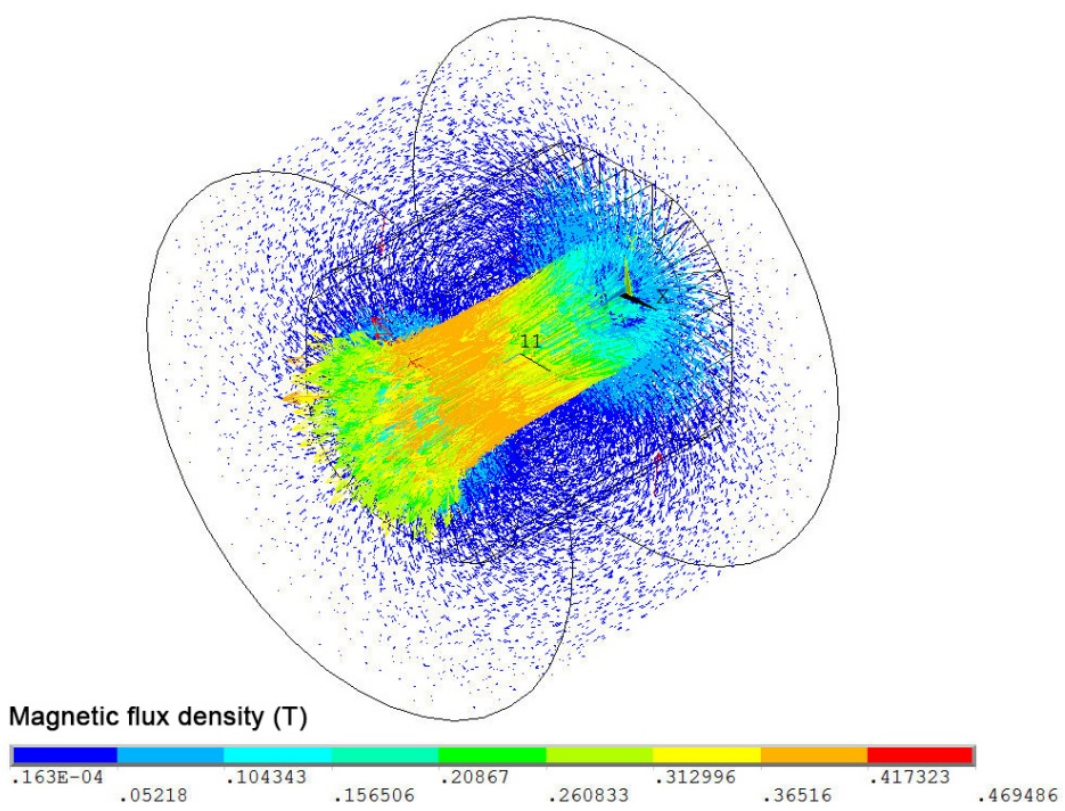

(b) Current $=1 \mathrm{~A}$. 


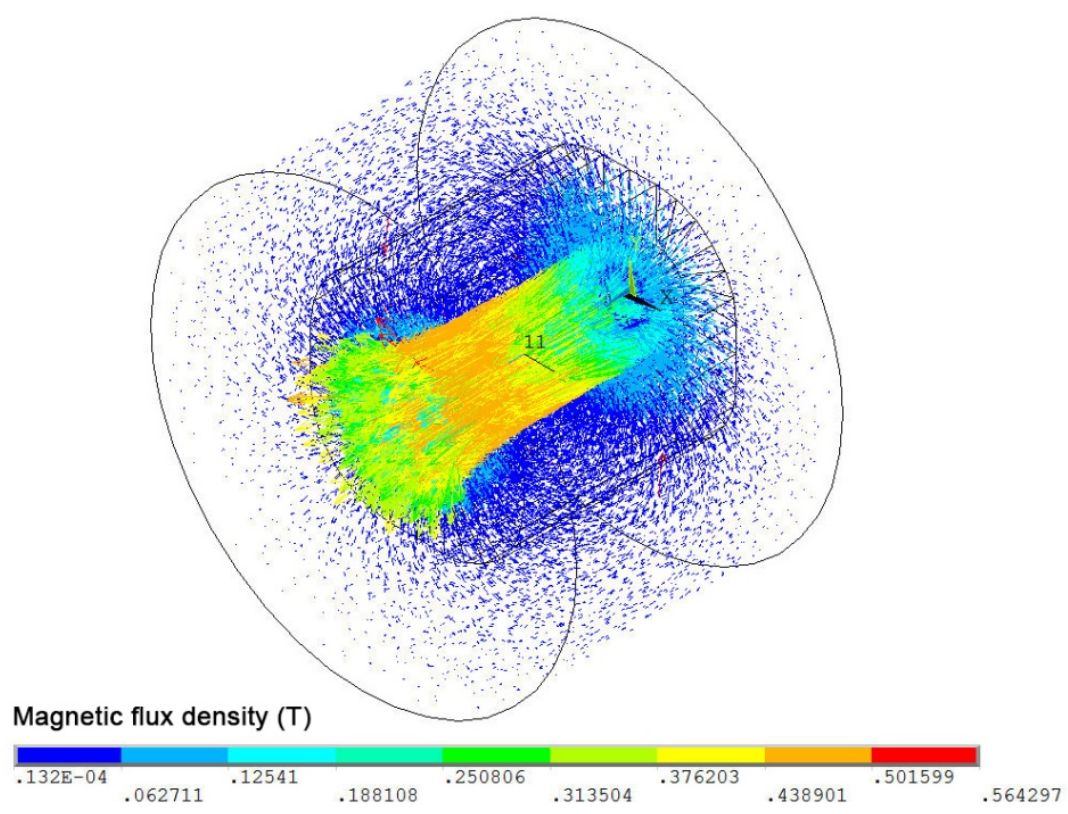

(c) Current $=1.5 \mathrm{~A}$.

Fig.3. Vector plot of magnetic flux density in the excited field.

The impact zone of fluid jet at the surface of target can be characterized as a high stagnation pressure. The distribution of the high pressure zone reflects the concentration extent of the MR jet. Fig. 4 shows the pressure distribution at the jet impact zone under different excitation currents. It can be drawn that the size of the high pressure zone decreases with an increase of the external magnetic flux density, which indicates that the concentration of MR jet is improved under the magnetic field. The pressure magnitude at the impact center rises from $395 \mathrm{KPa}$ to $793 \mathrm{KPa}$ when the excitation current increases from $0.5 \mathrm{~A}$ to $1.5 \mathrm{~A}$.
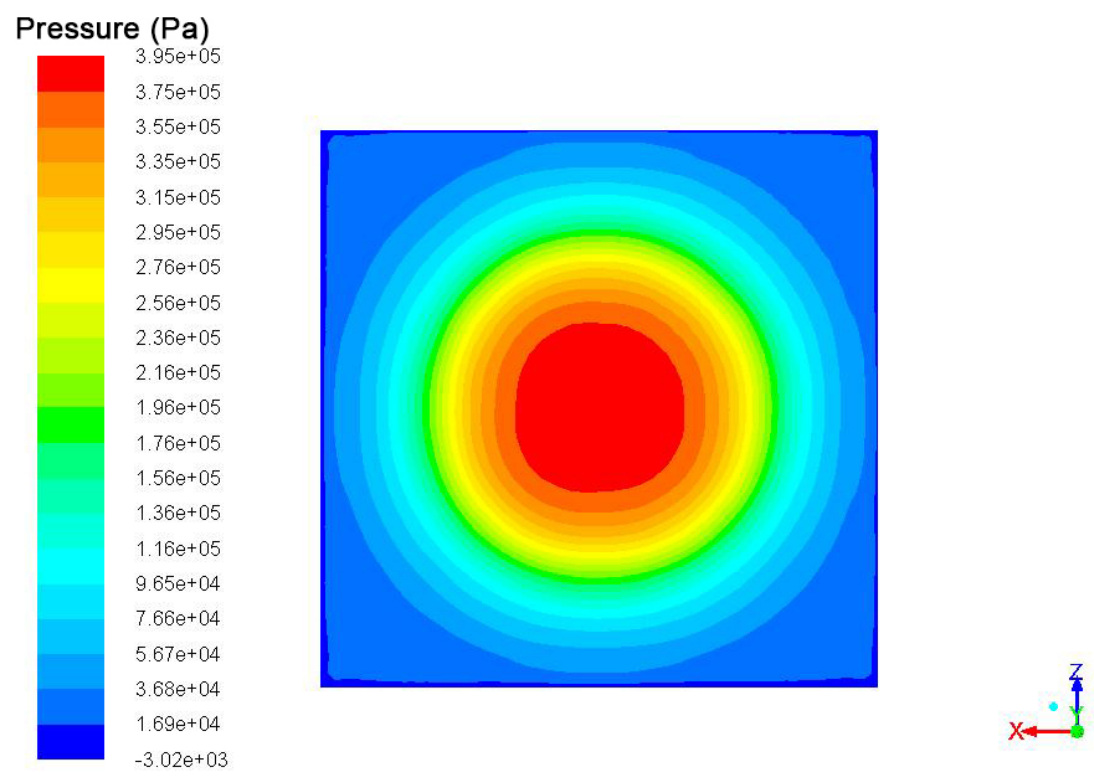

(a) Current $=0.5 \mathrm{~A}$. 

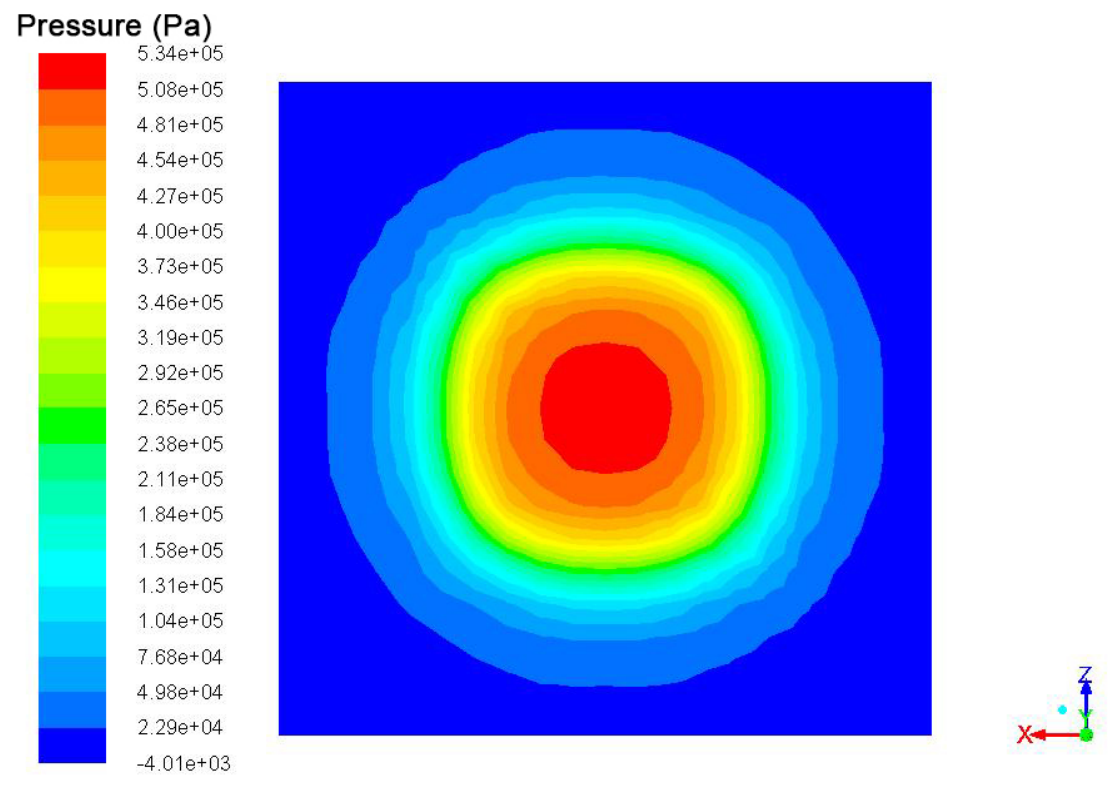

(b) Current $=1 \mathrm{~A}$.
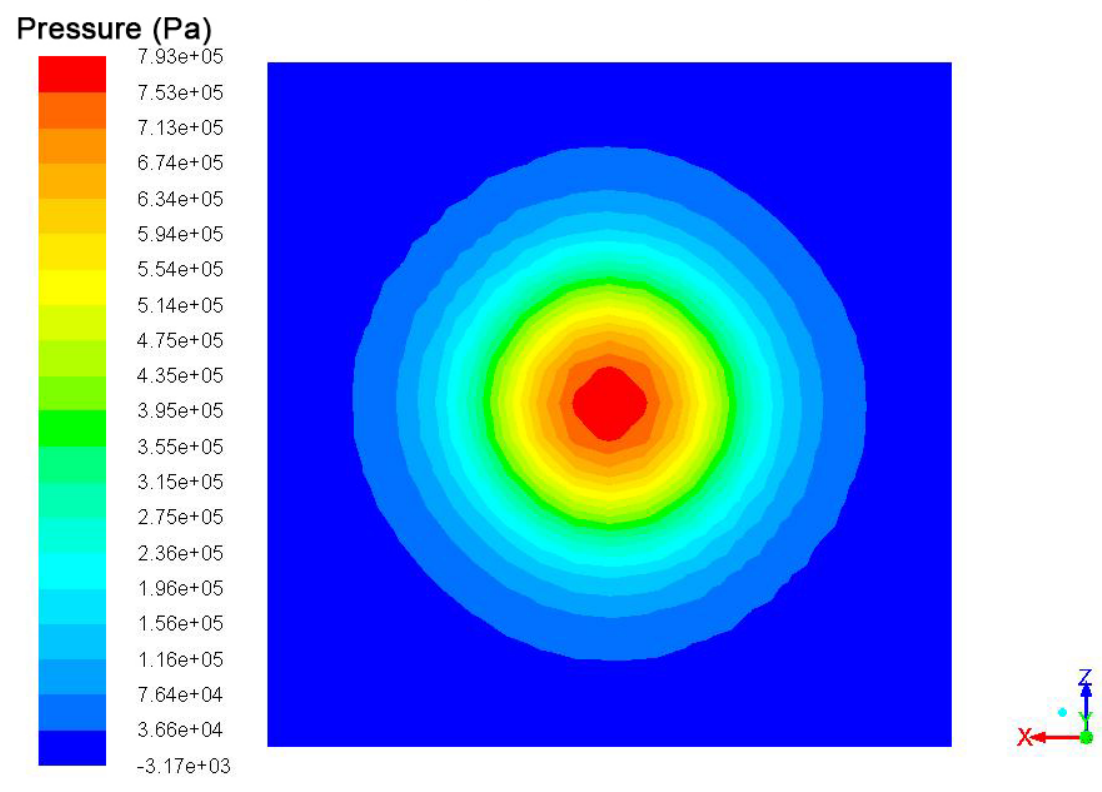

(c) Current $=1.5 \mathrm{~A}$.

Fig.4. Pressure contour on the target surface.

The tracks of abrasive particles are shown in Fig.5. The motion of abrasive particle is constrained by the carrier jet flow. It is obvious that the distance between trajectories of adjacent particles is shortened, which can be attributed to the inhibition of jet diffusion. At the near surface region, it can be found that impact angle of the individual abrasive particle increases. The rebound of abrasive particles is also suppressed by the MR jet flow. 


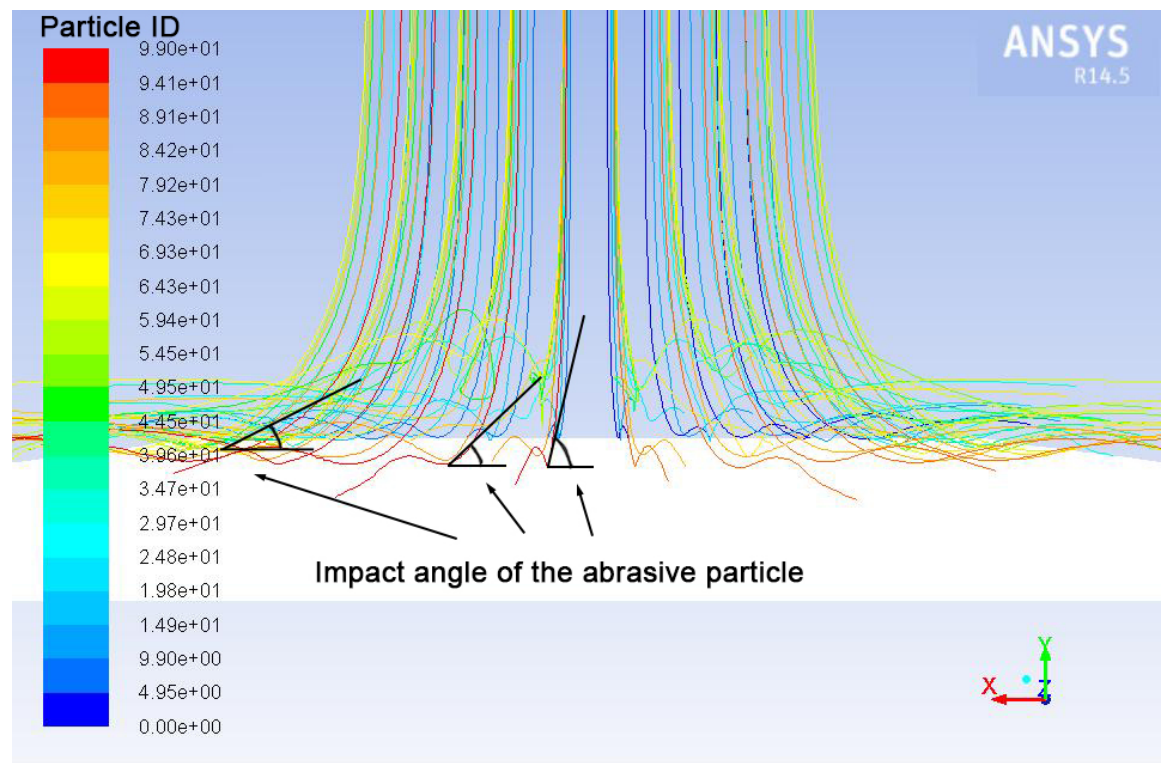

(a) Current $=0.5 \mathrm{~A}$.

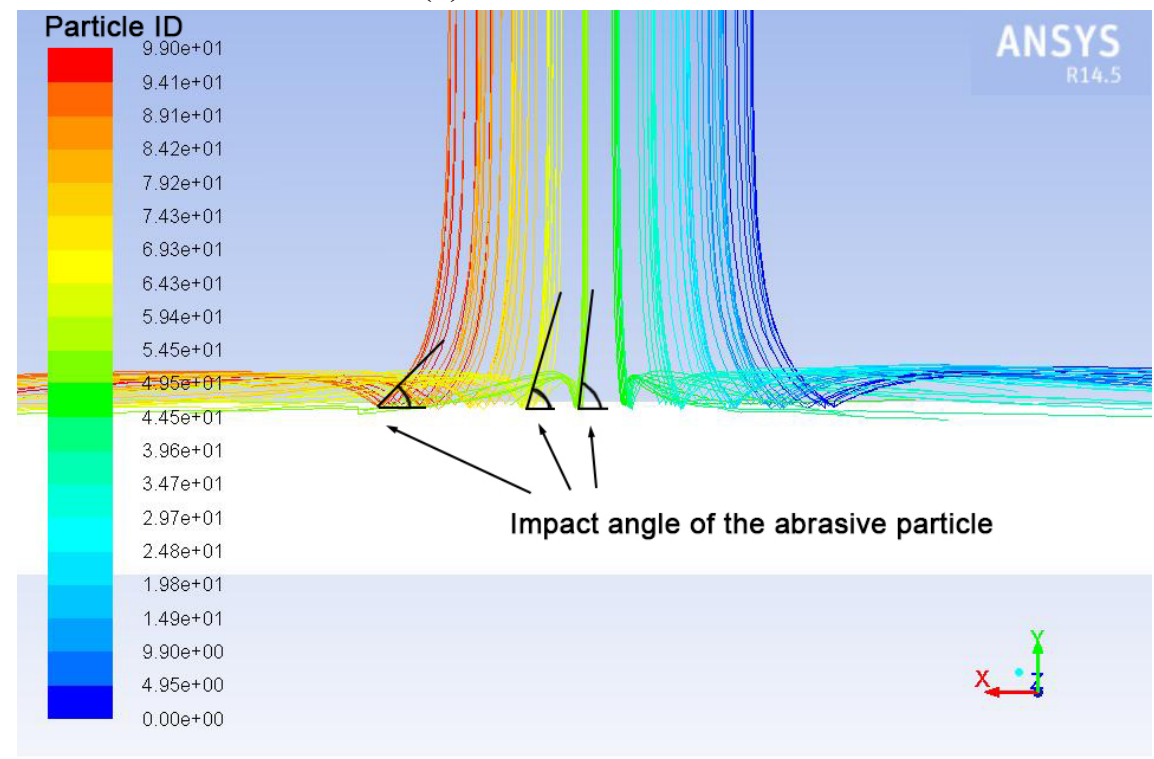

(b) Current $=1.5 \mathrm{~A}$.

Fig.5. Trajectories of abrasive particles laden in MR jet flow.

\section{Verification experiments}

\subsection{Experimental conditions}

The direct observation on physical aspects of jet flow such as pressure distribution and particle tracks is difficult to achieve. Therefore, erosion tests were implemented to investigate the MR jet flow characteristics. An abrasive waterjet machining setup associated with the magnetic field generator shown in Fig.6 was used to conduct the experiments. The abrasive particles were mixed with MR fluid in a chamber, and then the magnetic field was applied on the particles laden flow. The magnetic flux density can be adjusted by changing the excitation current of the coil. 


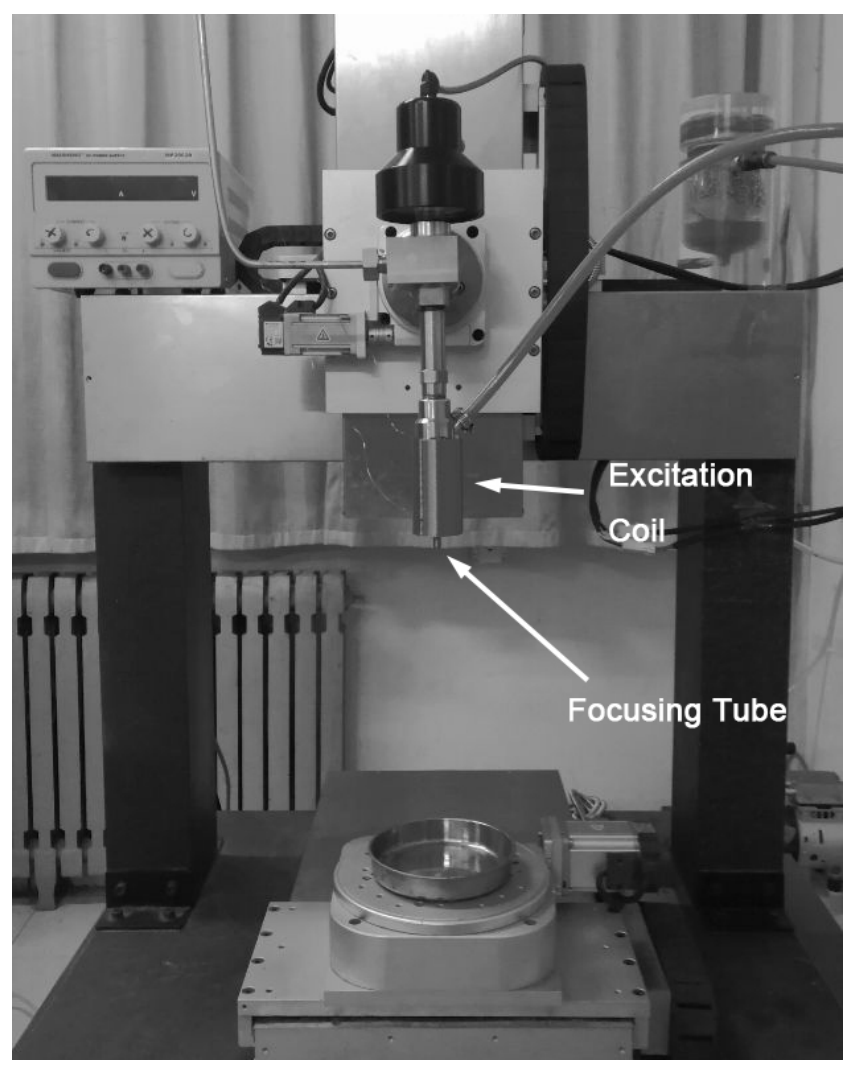

Fig.6. Experimental setup of MR jet erosion.

The material of workpiece is chosen as the aluminum oxide, which is a commonly used type of ceramic. The abrasive material is silicon carbide, and the average diameter of the powder is $15 \mu \mathrm{m}$. The MR fluid is mixed by water, wt $5 \%$ hydroxyl iron powder and wt $1 \%$ carbowax. In addition to the erosion tests, the feasibility of utilizing MR jet in surface finishing has also been explored. The surfaces of aluminum oxide specimens with the initial surface roughness of Ra $1.3 \mu \mathrm{m}$ were processed by using MR jet. Some main processing conditions of erosion and finishing tests are listed in Table 1.

Table 1. Processing conditions

\begin{tabular}{ll}
\hline Parameters & \\
\hline Current on coil $[\mathrm{A}]$ & $0-1.5$ \\
Turn number of coil & 2000 \\
length of coil $[\mathrm{mm}]$ & 80 \\
Focusing tube outlet diameter $[\mathrm{mm}]$ & 1 \\
Standoff distance $[\mathrm{mm}]$ & 25 \\
Pressure $[\mathrm{MPa}]$ & 20 \\
Abrasive flow rate $[\mathrm{g} / \mathrm{s}]$ & 1 \\
Erosion time $[\mathrm{s}]$ & 1 \\
Travers speed of finishing $[\mathrm{mm} / \mathrm{s}]$ & 2 \\
\hline
\end{tabular}




\subsection{Experimental results and discussions}

Material removal mechanism has a strong reliance on the interaction between active abrasive particles and the workpiece surface. Therefore, the processed surface is visualized by utilizing laser scanning microscope. The topography of eroded surface is shown in Fig.7. It can be found that the area of crater eroded by MR jet under the current of $1.5 \mathrm{~A}$ is smaller, and the depth of the crater is greater. The area of crater is dependent on the cover range of incident particles laden in the flow jet. Therefore, this fact can verify the simulation result that the trajectories of particles concentrate well under external magnetic field.

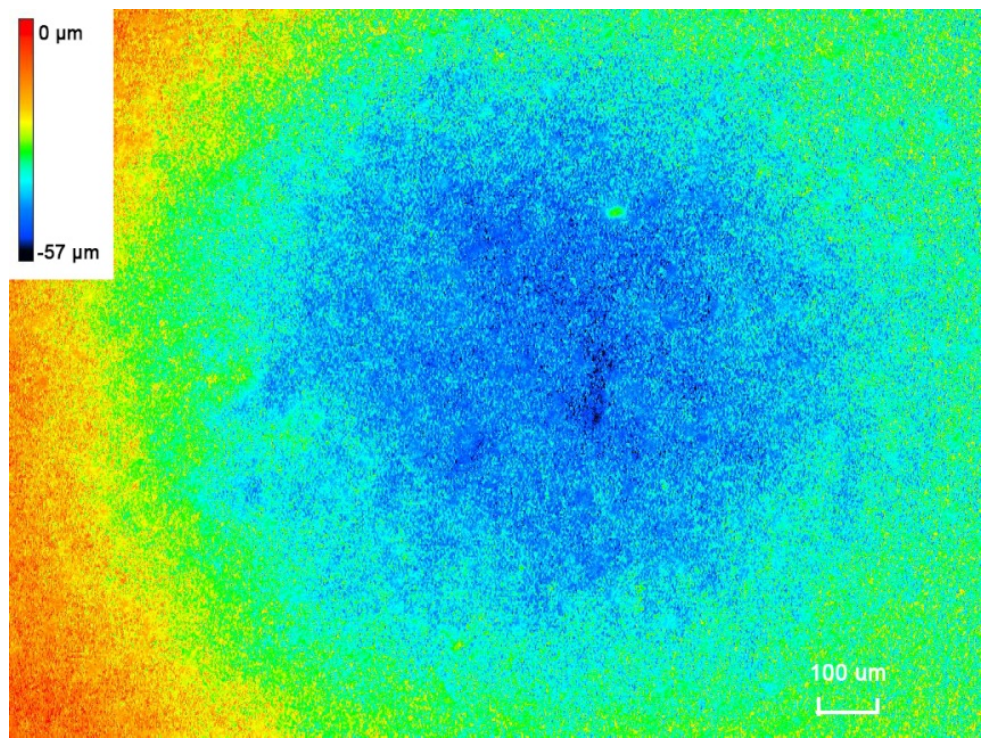

(a) $0 \mathrm{~A}$

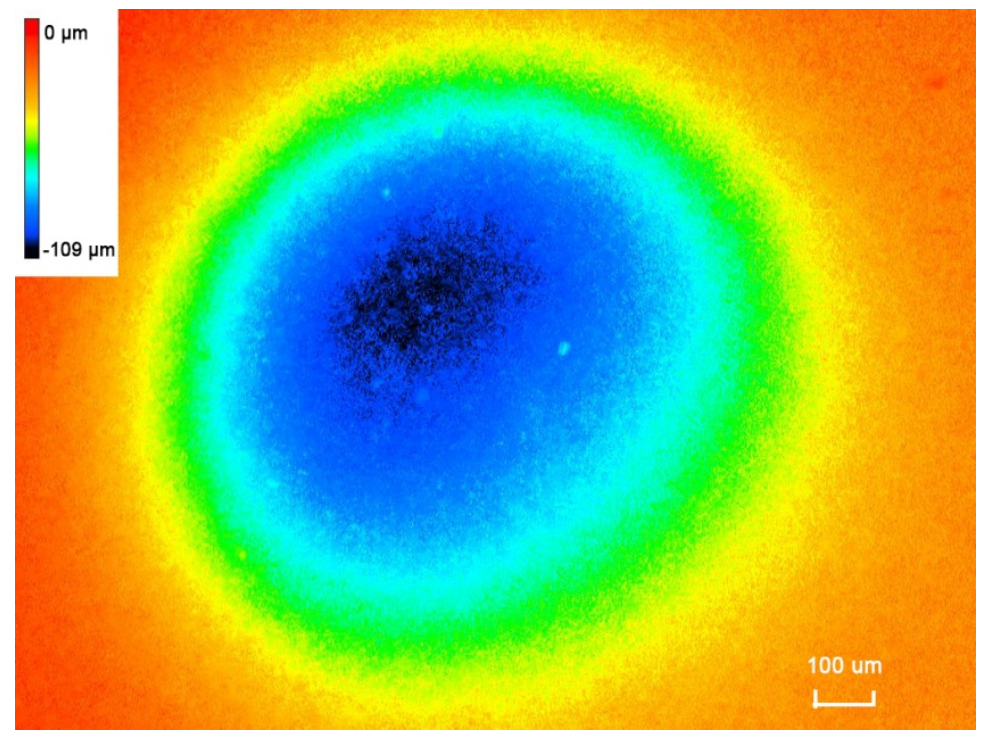

(b) $1.5 \mathrm{~A}$

Fig.7. The topography of eroded crater on target surface by MR jet.

The erosion rates under different conditions are shown in Fig.8. It can be found that the erosion rate under external magnetic field is obviously higher. This can be 
attributed to the increased concentration of MR jet. Moreover, the erosion rate increases with an increment of excitation current due to the enhanced magnetic flux density. The viscosity of magnetorheological fluid increases under high magnetic flux intensity and therefore the divergence of jet flow can be effectively restrained. Based on the findings of Humphrey [14], Abrasive particles laden in fluid are more likely to follow the streamline when the viscosity is higher. This tendency can be interpreted by the momentum equilibrium number $\lambda$ :

$$
\lambda=\frac{\rho_{p}\left(d_{p}\right)^{2} v_{j}}{18 \mu d_{n}}
$$

Where $\rho_{d}$ is the particle density, $d_{p}$ is the particle diameter, $v_{j}$ is the jet velocity, $\mu$ is the viscosity and $d_{n}$ is the nozzle diameter. Following the high viscosity jet, abrasive particles laden in magnetorheological fluid tend to take the effect of abrading target material at the impinging zone rather than dispersed with the lateral flow. The experimental result coincides well with the simulation fact that the improved concentration of jet and laden particles under external magnetic field. From the analysis of the simulation result, the impact angle of the individual abrasive particle increases due to the improved concentration. The deformation wear induced by the impact of a single abrasive particle can be expressed as [15]:

$$
W_{D}=\frac{0.5 m(v \sin \alpha-K)^{2}}{\varepsilon}
$$

Where $\mathrm{m}$ is the mass of a single particle, $\mathrm{v}$ is the velocity, $\alpha$ is the impact angle, $\mathrm{K}$ is the velocity component at which the damage limit is just reached. $\varepsilon$ is the energy needed to remove a unit volume of material. It can be drawn that an increase of impact angle $\alpha$ can also lead to the improvement of erosion.

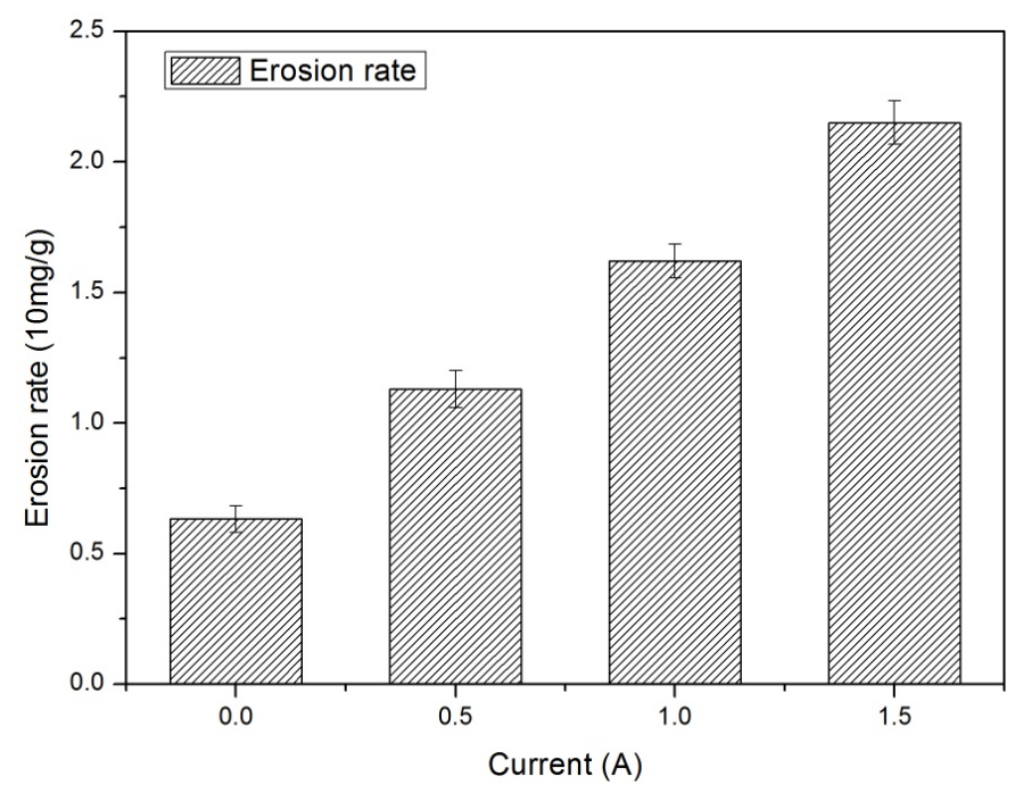

Fig.8. The variation of erosion rate with excitation current.

The finished surface by MR jet is shown in Fig.9. For guaranteeing the surface integrity of the processed surface, the incident angle of MR jet is lower than that used 
in erosion test. It can be observed from Fig.9 (a) that some inherent surface features remain on the processed surface. This can be attributed to the relatively moderate plowing mechanism of abrasive particles under low magnetic flux intensity. The holding effect of carrier fluid flow is not enough and the penetrations of active particles are lower, which results in the ineffectively removal of surface peaks. From Fig.9 (b), it can be observed that continuous abrasion grooves almost cover the whole surface, which indicates that the original peaks has been entirely removed by the shearing and micro cutting mechanism of abrasive particles.

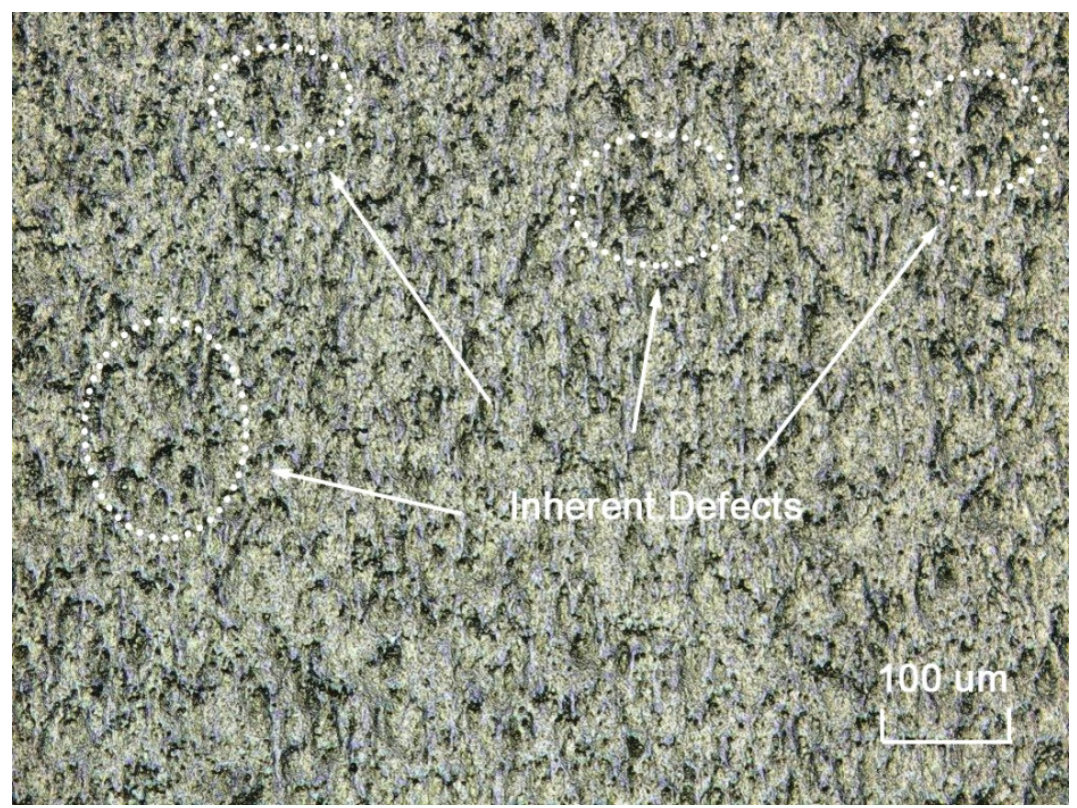

(a) $0.5 \mathrm{~A}$

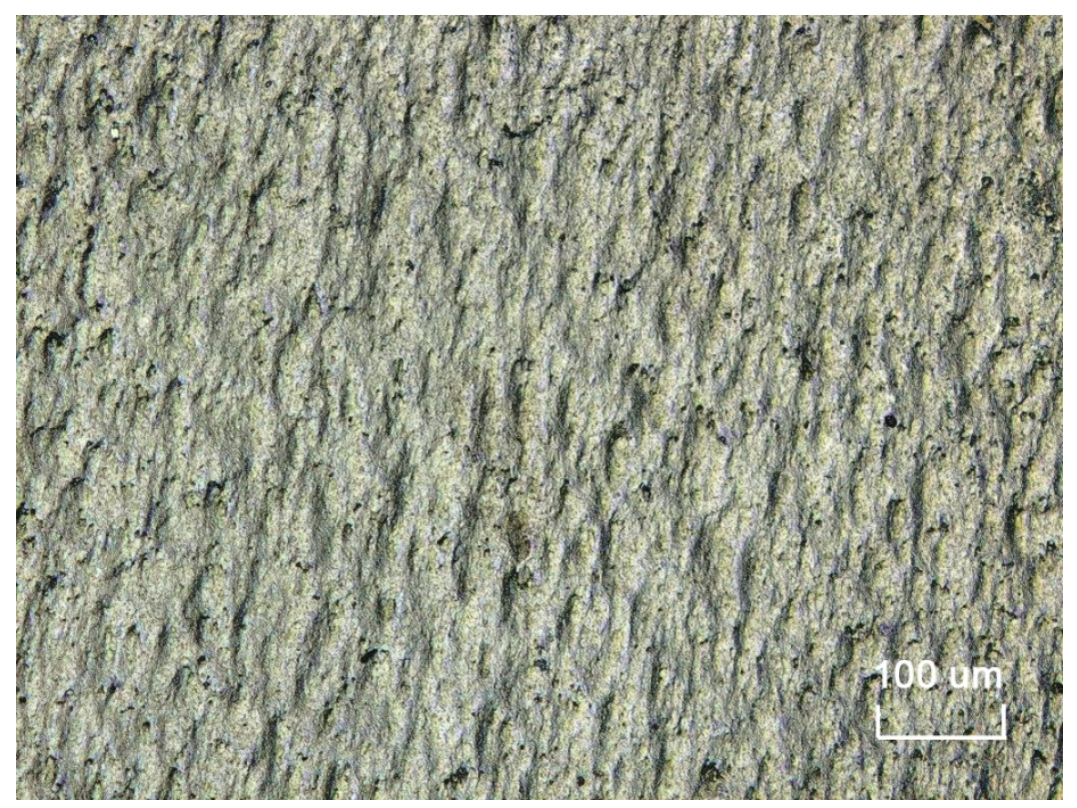

(b) $1.5 \mathrm{~A}$

Fig.9. The finished surface by MR jet under different current.

Fig.10 shows the variation of surface roughness after MR jet finishing. It can be found that the percentage reduction of surface roughness increases with an increase of current in excitation coil. This can be attributed to the stronger magnetic field. The 
penetration of abrasive particles in the bunching jet under high magnetic flux intensity is intensive, and therefore results in more micro cutting and shearing of material from the peaks of target surface. The increased amount wear of material is helpful for the improvement of surface quality.

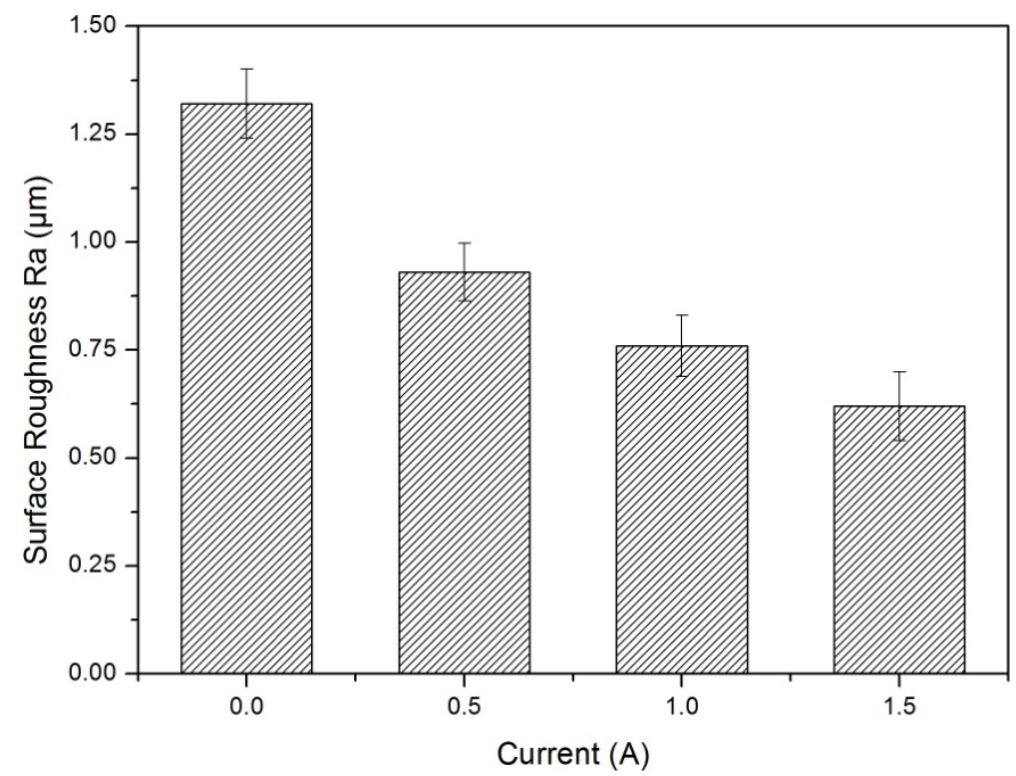

Fig.10. The variation of surface roughness with excitation current.

\section{Conclusions}

The flow characteristics of MR jet under external magnetic field have been analyzed by establishing numerical models. Experiments were conducted to verify the simulation results and asses the feasibility for the utilization of MR jet in surface finishing. The simulation results indicated that the size of the high pressure zone at the impacted area decreases and the pressure magnitude at the impact center rises with an increase of the applied external magnetic flux density. The trajectories of particles concentrate well with the application of external magnetic field, and the impact angles of abrasive particles laden in jet flow increase. The results of erosion test indicated that the depth of erosion crater is greater and the area is smaller when higher excitation current is applied, which verifies that the diffusion of flow jet is significantly inhibited. The results of finishing experiments indicated that fine surfaces can be obtained by using MR jet processing. The utilization of high magnetic intensity can improve the processing quality. The investigation can give some guidelines for the practical utilization of MR jet machining. 


\section{Declarations}

\section{Funding}

This work is supported by National Natural Science Foundation of China (51405274).

\section{Conflicts of interest/Competing interests}

Not applicable

\section{Availability of data and material}

Not applicable

\section{Code availability}

The software used in the present study is authorized.

\section{Authors' contributions}

Zhe Lv completed the main work of writing, simulation and experimental works, Rongguo Hou conducted part of the simulation work, Ping Lu and Xiangtian Wang conducted parts of the experimental works.

\section{Acknowledgements}

This work is supported by National Natural Science Foundation of China (51405274).

\section{References}

1. Haj Mohammad Jafar R, Nouraei H, Emamifar M, Papini M, Spelt JK (2014) Erosion modeling in abrasive slurry jet micro-machining of brittle materials. $\mathrm{J}$ Manuf Process. doi: 10.1016/j.jmapro.2014.08.006

2. Nouraei H, Kowsari K, Samareh B, Spelt JK, Papini M (2016) Calibrated CFD erosion modeling of abrasive slurry jet micro-machining of channels in ductile materials. J Manuf Process 23:90-101. doi: 10.1016/j.jmapro.2016.06.007

3. Chen F, Hao S, Miao X, Yin S, Huang S (2018) Numerical and experimental study on low-pressure abrasive flow polishing of rectangular microgroove. 
Powder Technol 327:215-222. doi: 10.1016/j.powtec.2017.12.062

4. Liu D, Huang C, Wang J, Zhu H, Yao P, Liu Z (2014) Modeling and optimization of operating parameters for abrasive waterjet turning alumina ceramics using response surface methodology combined with Box-Behnken design. Ceram Int 40:7899-7908. doi: 10.1016/j.ceramint.2013.12.137

5. Kowsari K, Nouraei H, James DF, Spelt JK, Papini M (2014) Abrasive slurry jet micro-machining of holes in brittle and ductile materials. J Mater Process Technol 214:1909-1920. doi: 10.1016/j.jmatprotec.2014.04.008

6. Long X, Ruan X, Liu Q, Chen Z, Xue S, Wu Z (2017) Numerical investigation on the internal flow and the particle movement in the abrasive waterjet nozzle. Powder Technol 314:635-640. doi: 10.1016/j.powtec.2016.09.089

7. Jacobs SD, Golini D, Hsu Y, Puchebner BE, Strafford D, Prokhorov I V, Fess EM, Pietrowski D, Kordonski WI (1995) Magnetorheological finishing: a deterministic process for optics manufacturing. In: Kasai T (ed) International Conference on Optical Fabrication and Testing. pp 372-382

8. Khatri N, Xavier Manoj J, Mishra V, Garg H, Karar V (2018) Experimental and simulation study of nanometric surface roughness generated during Magnetorheological finishing of Silicon. Mater Today Proc 5:6391-6400. doi: 10.1016/j.matpr.2017.12.250

9. Saraswathamma K, Jha S, Rao P V. (2015) Experimental investigation into Ball end Magnetorheological Finishing of silicon. Precis Eng 42:218-223. doi: 10.1016/j.precisioneng.2015.05.003

10. Sidpara A, Jain VK (2013) Analysis of forces on the freeform surface in magnetorheological fluid based finishing process. Int J Mach Tools Manuf 69:1-10. doi: 10.1016/j.ijmachtools.2013.02.004

11. Tricard M, Kordonski WI, Shorey AB (2006) Magnetorheological jet finishing of conformal, freeform and steep concave optics. CIRP Ann - Manuf Technol 55:309-312. doi: 10.1016/S0007-8506(07)60423-5

12. Kim WB, Nam E, Min BK, Choi DS, Je TJ, Jeon EC (2015) Material removal of glass by magnetorheological fluid jet. Int J Precis Eng Manuf 16:629-637. doi: 10.1007/s12541-015-0084-3

13. Jayswal SC, Jain VK, Dixit PM (2005) Modeling and simulation of magnetic abrasive finishing process. Int J Adv Manuf Technol 26:477-490. doi: 10.1007/s00170-004-2180-x

14. Humphrey JAC (1990) Fundamentals of fluid motion in erosion by solid particle impact. Int J Heat Fluid Flow 11:170-195. doi:

10.1016/0142-727X(90)90036-B

15. Bitter J (1963) A study of erosion phenomena part II. Wear 6:169-190. doi: 10.1016/0043-1648(63)90073-5 
Figures

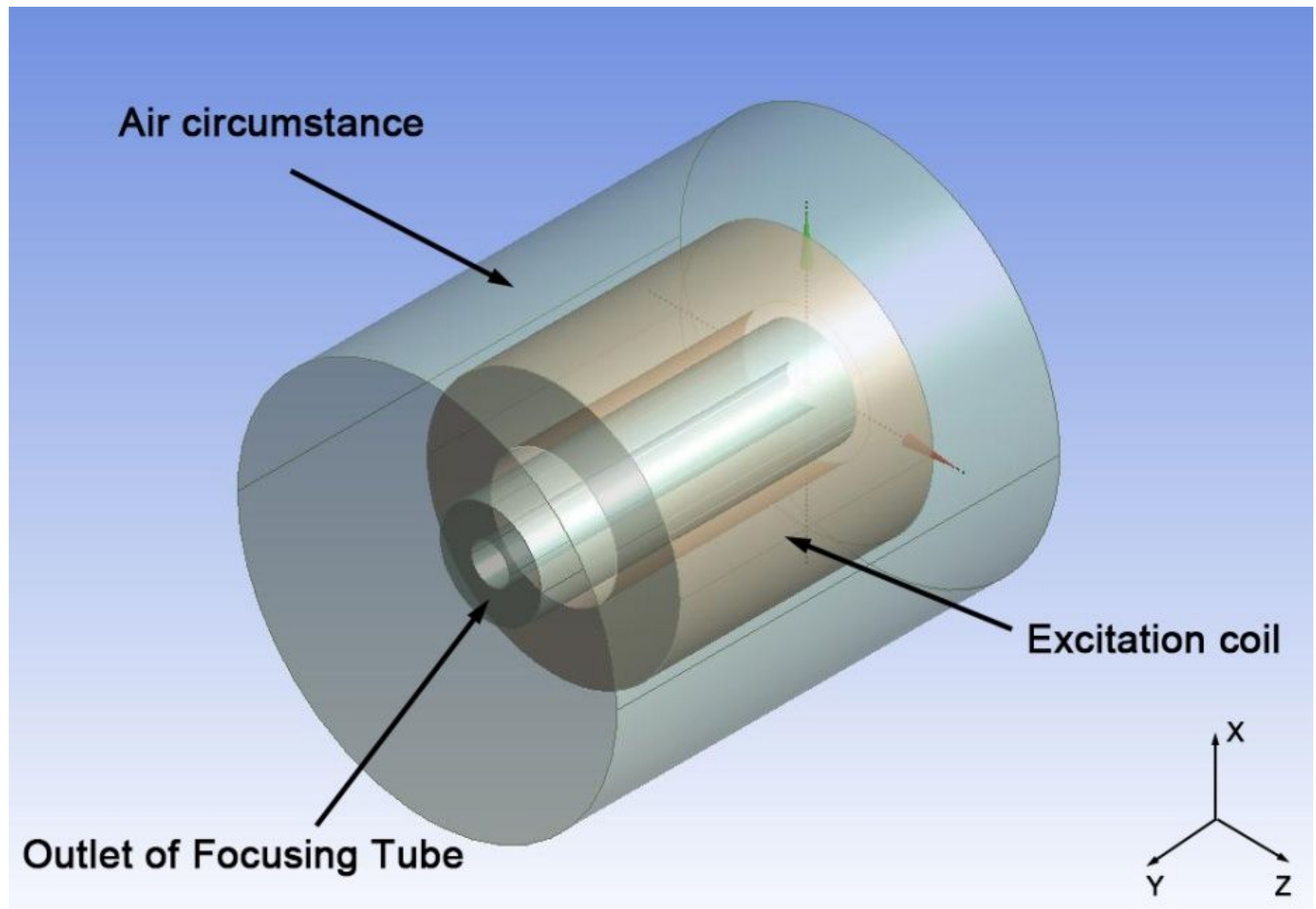

Figure 1

Computational domain of the electromagnetic field. 


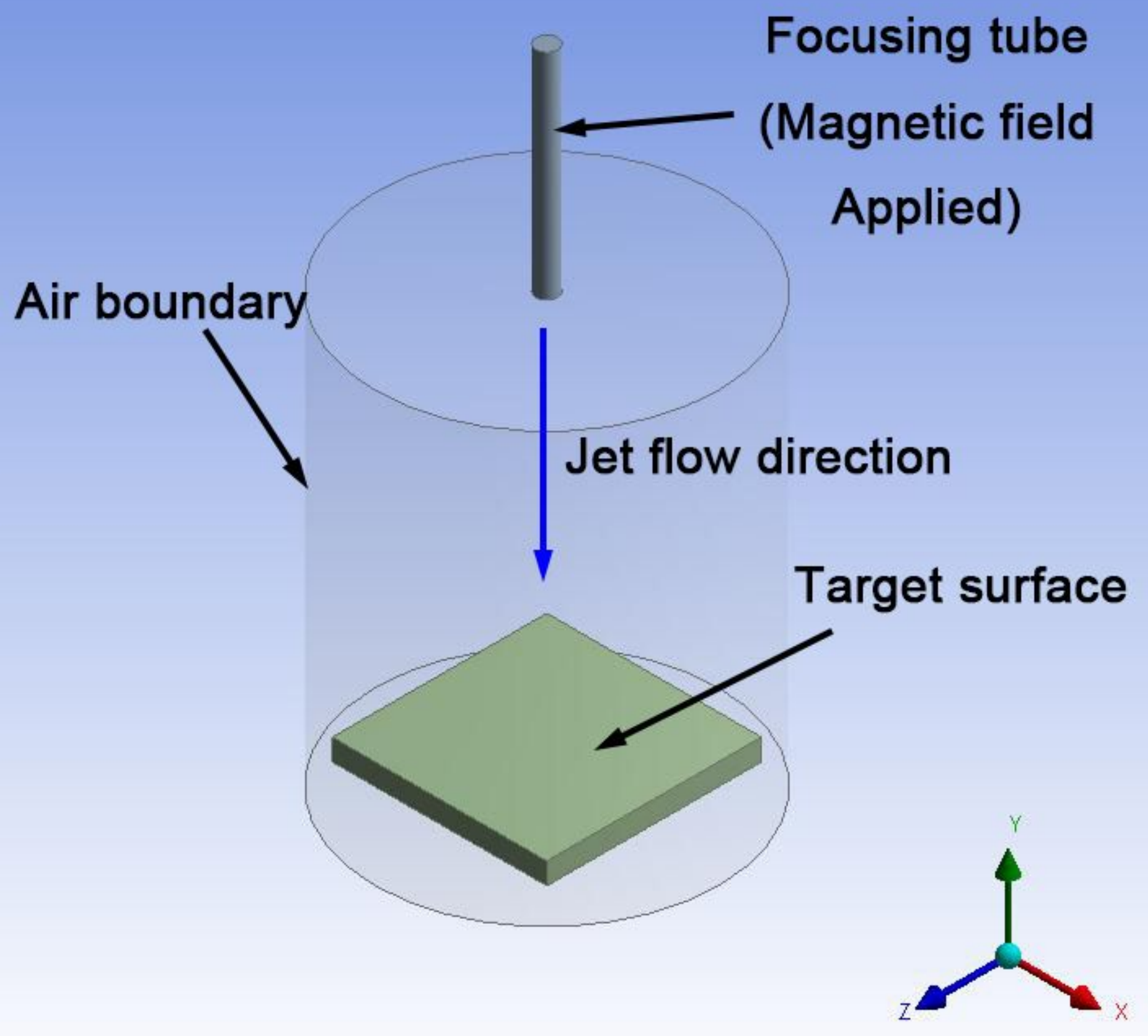

Figure 2

Geometric model of the jet flow field. 


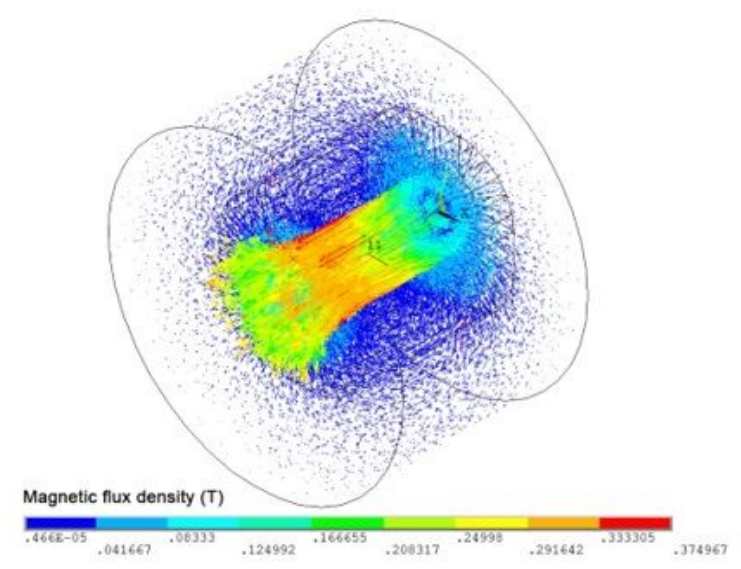

(a) Current $=0.5 \mathrm{~A}$.

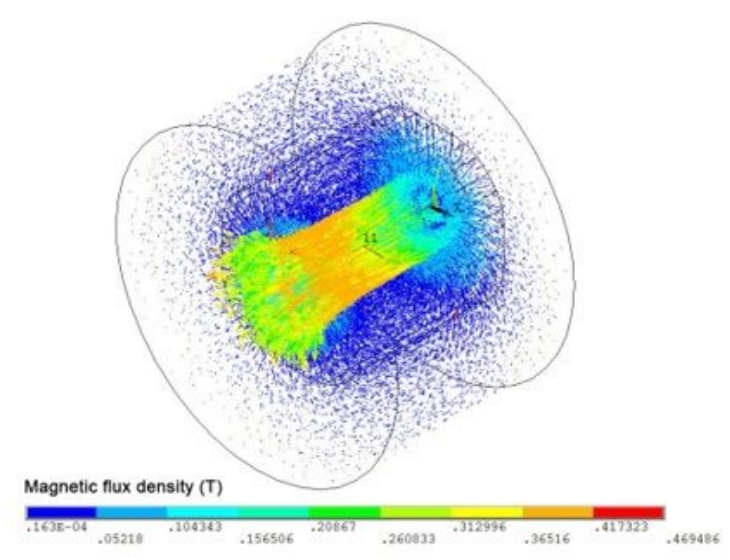

(b) Current $=1 \mathrm{~A}$.

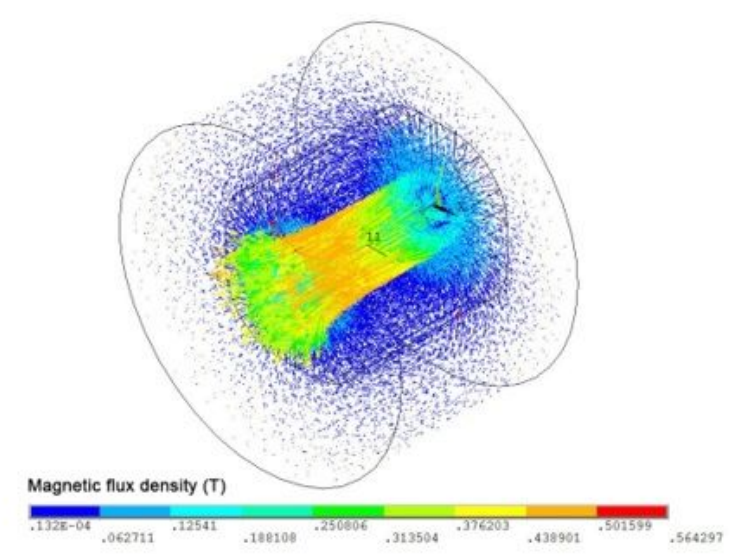

(c) Current $=1.5 \mathrm{~A}$.

Figure 3

Vector plot of magnetic flux density in the excited field. 
Pressure (Pa)

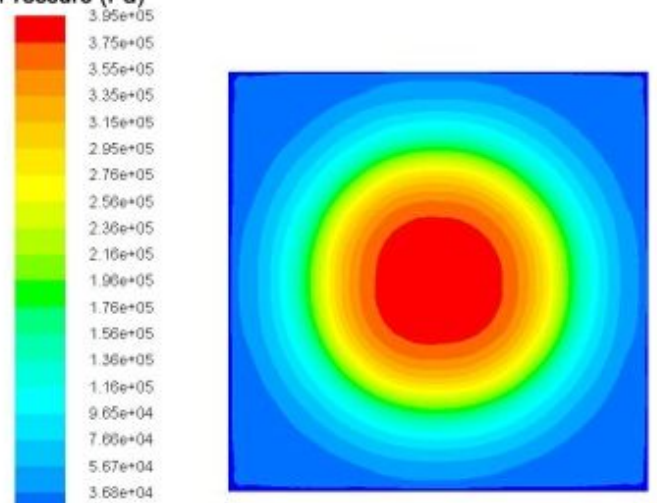

$x$

(a) Current $=0.5 \mathrm{~A}$.

Pressure $(\mathrm{Pa})$

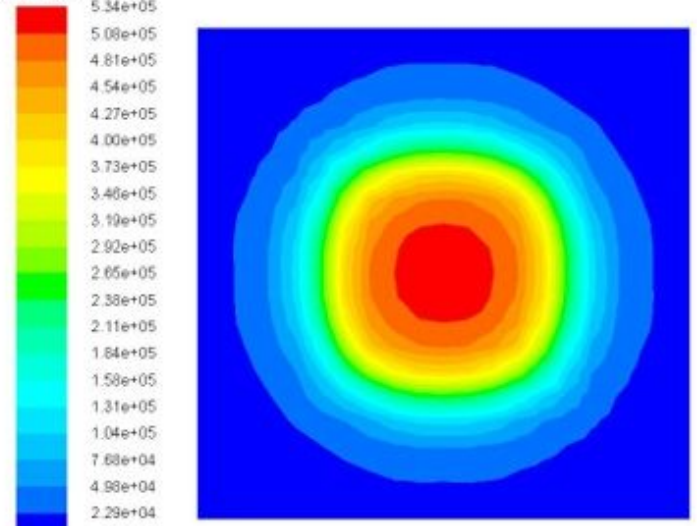

$x$

(b) Current $=1 \mathrm{~A}$.

Pressure $(\mathrm{Pa})$

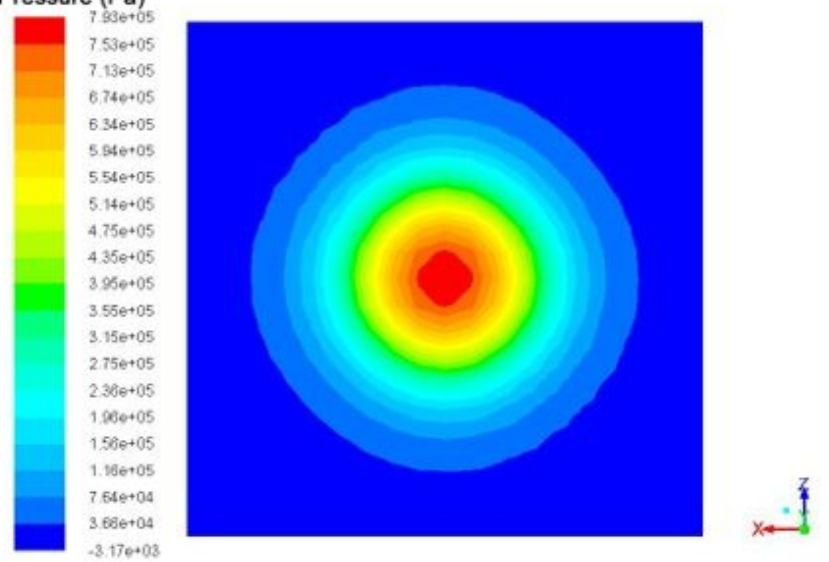

(c) Current $=1.5 \mathrm{~A}$.

Figure 4

Pressure contour on the target surface. 


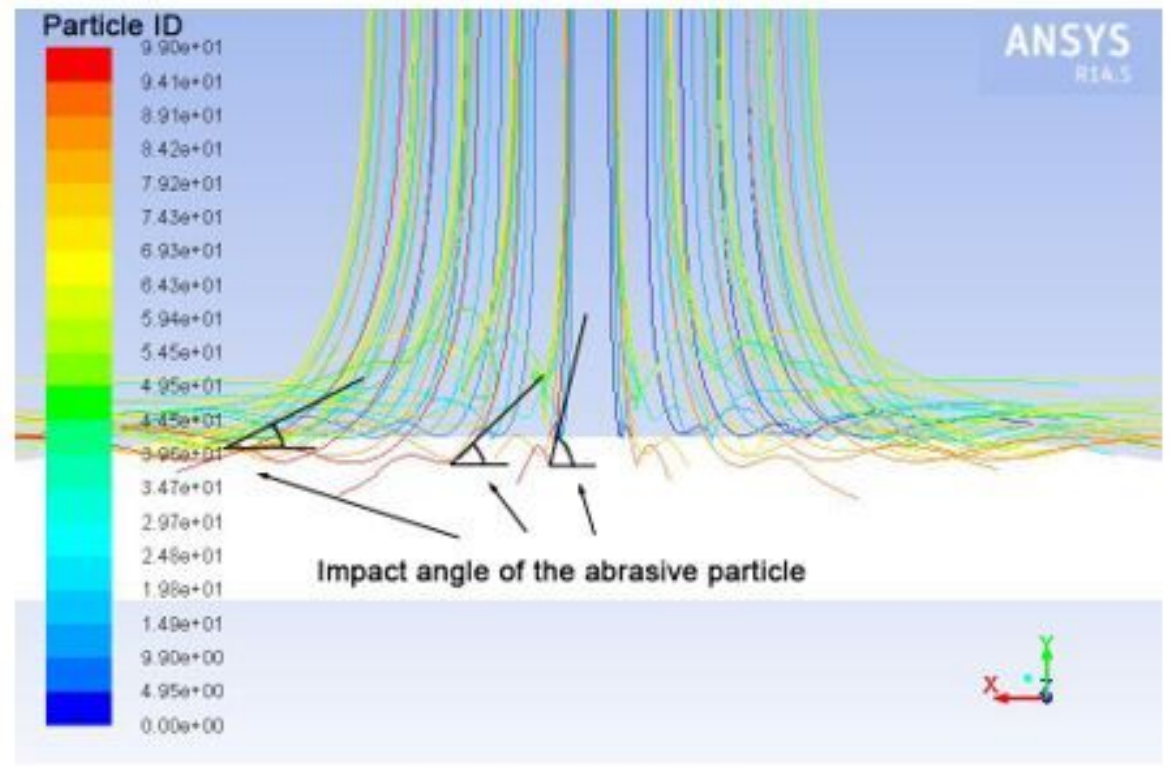

(a) Current $=0.5 \mathrm{~A}$.

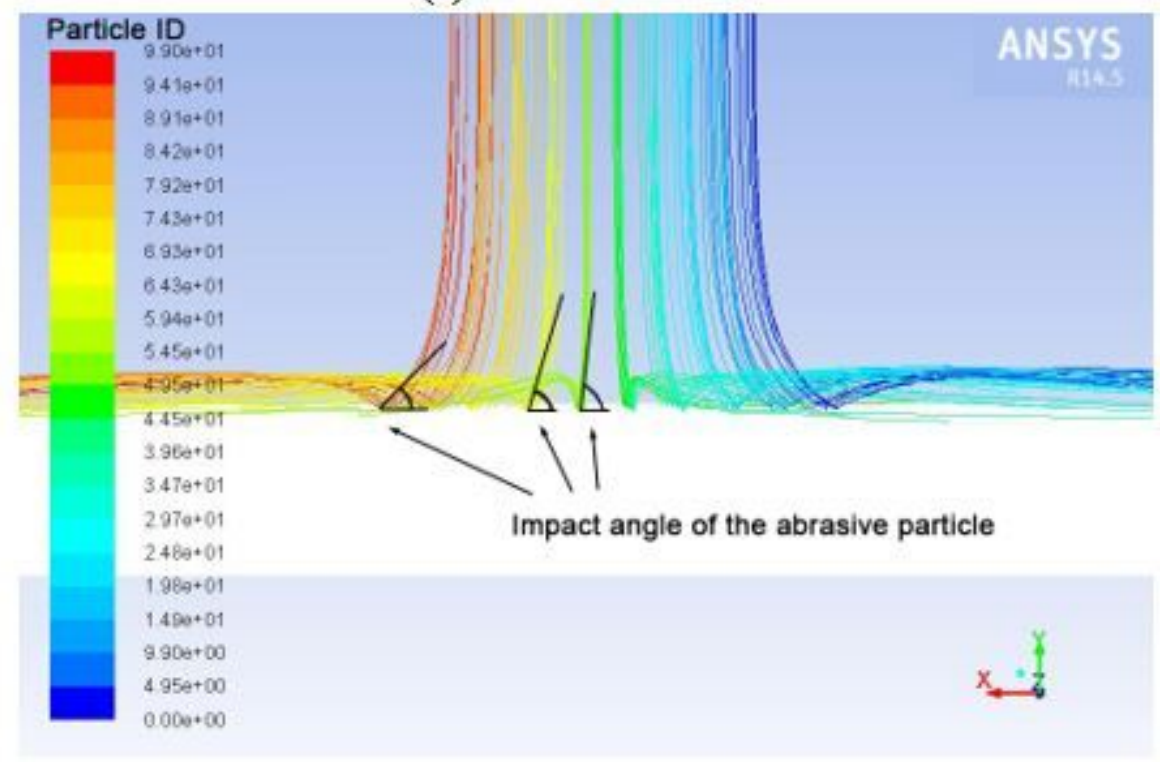

(b) Current $=1.5 \mathrm{~A}$.

\section{Figure 5}

Trajectories of abrasive particles laden in MR jet flow. 


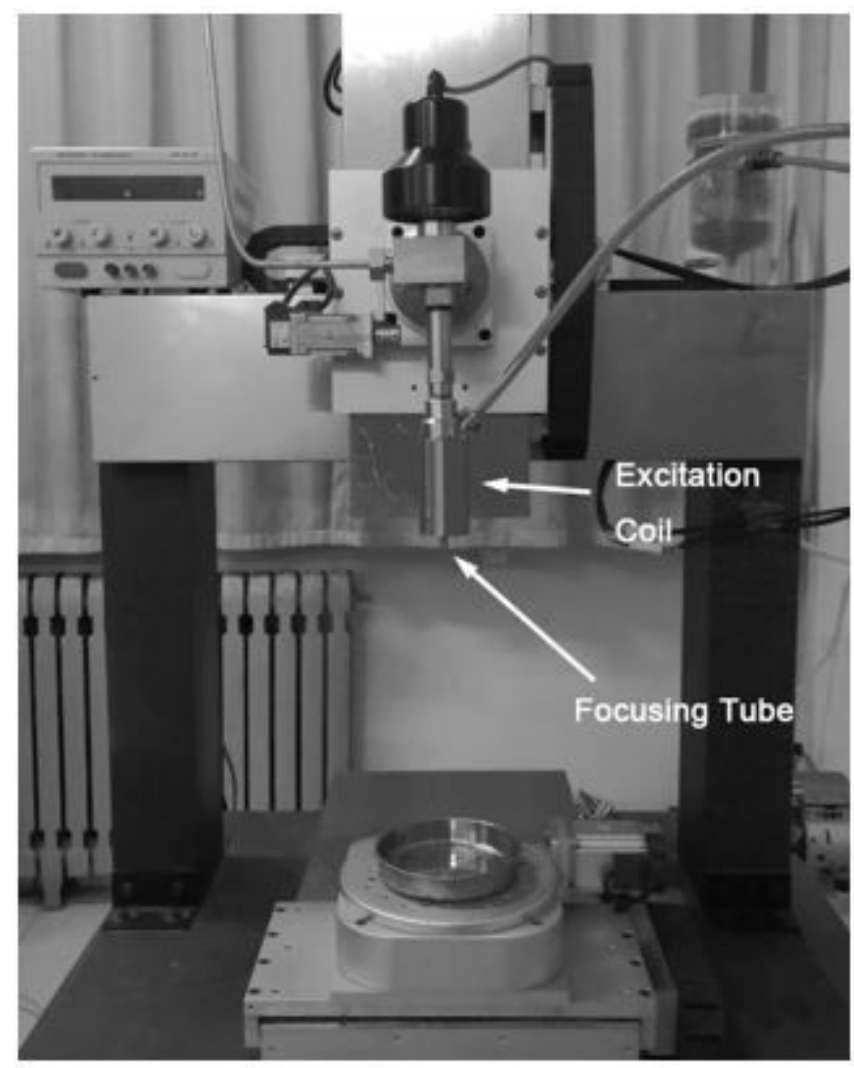

Figure 6

Experimental setup of MR jet erosion. 


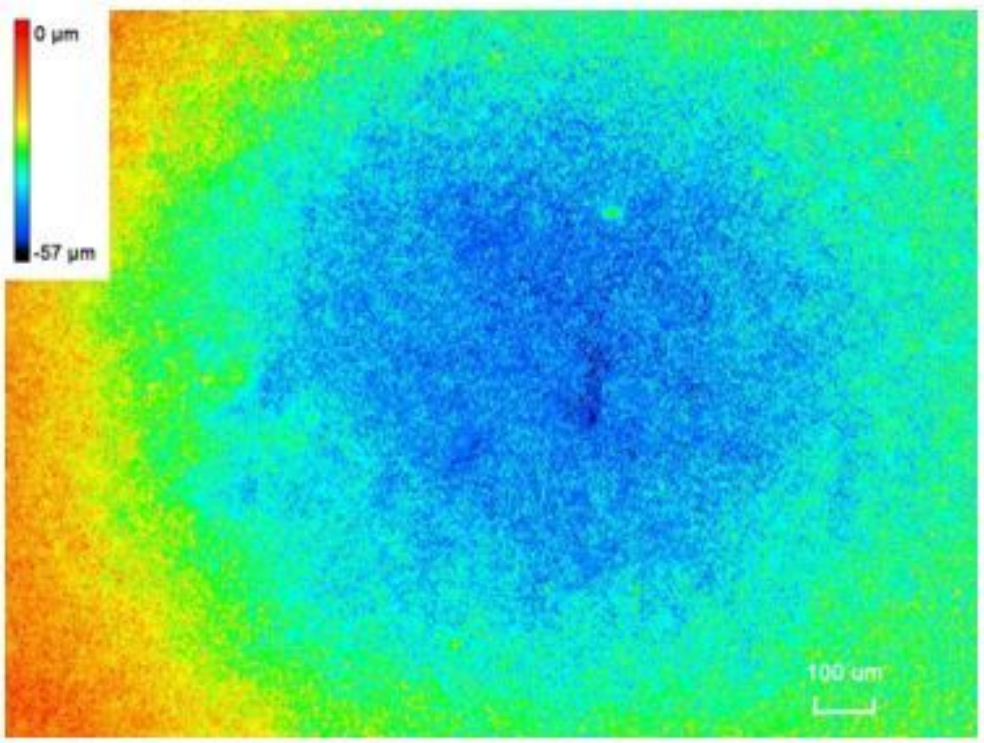

(a) $0 \mathrm{~A}$

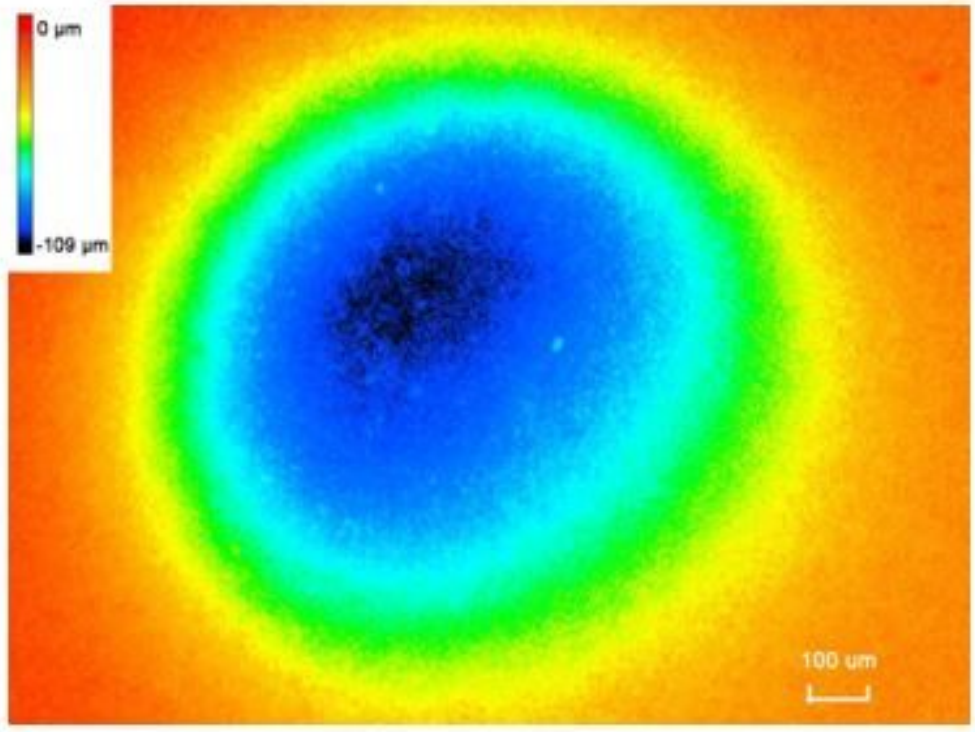

(b) $1.5 \mathrm{~A}$

Figure 7

The topography of eroded crater on target surface by MR jet. 


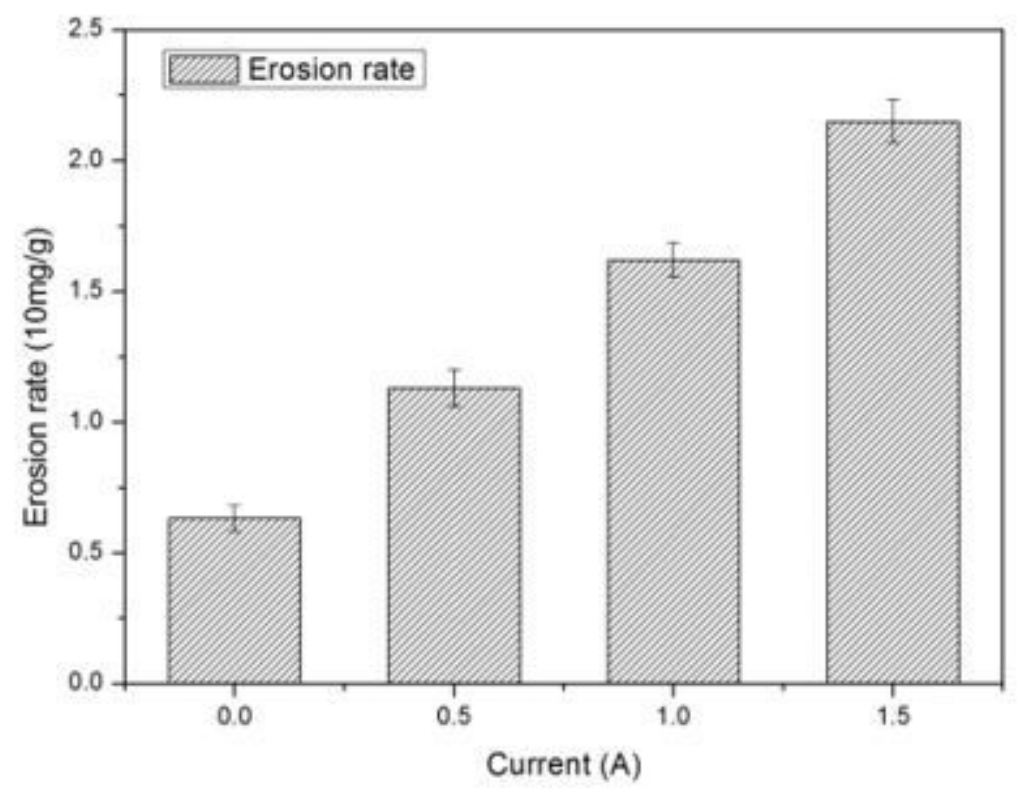

Figure 8

The variation of erosion rate with excitation current. 


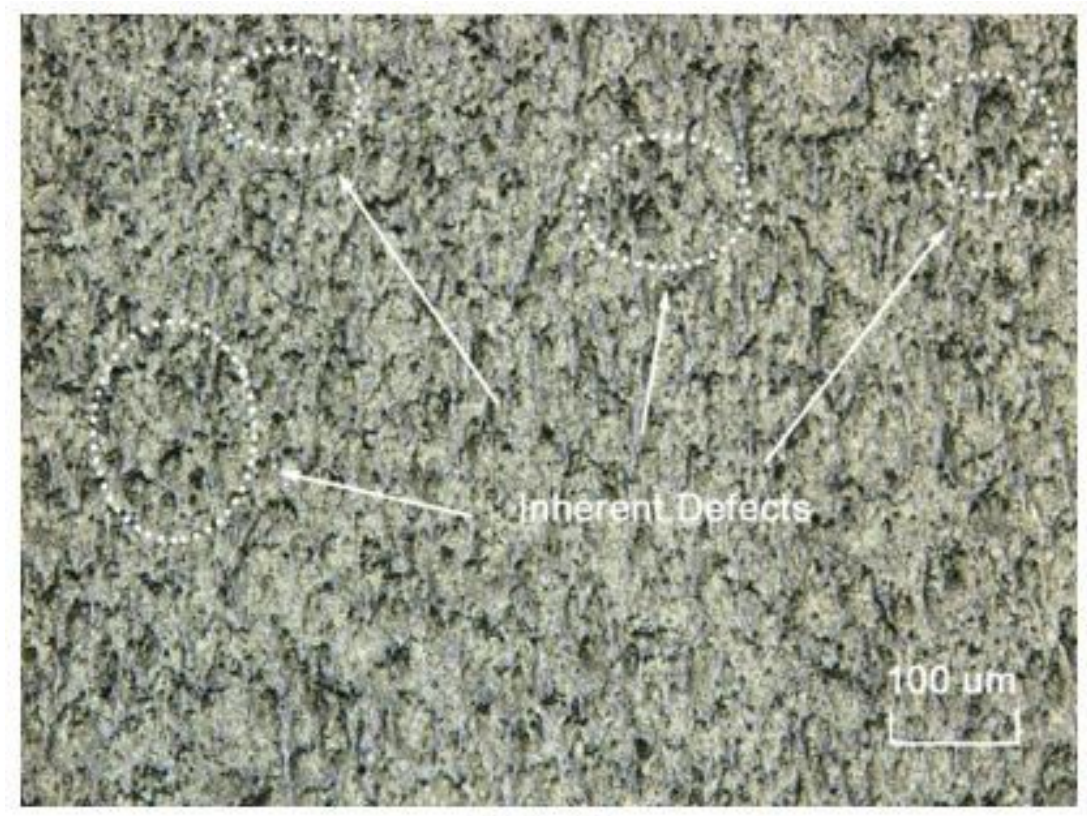

(a) $0.5 \mathrm{~A}$

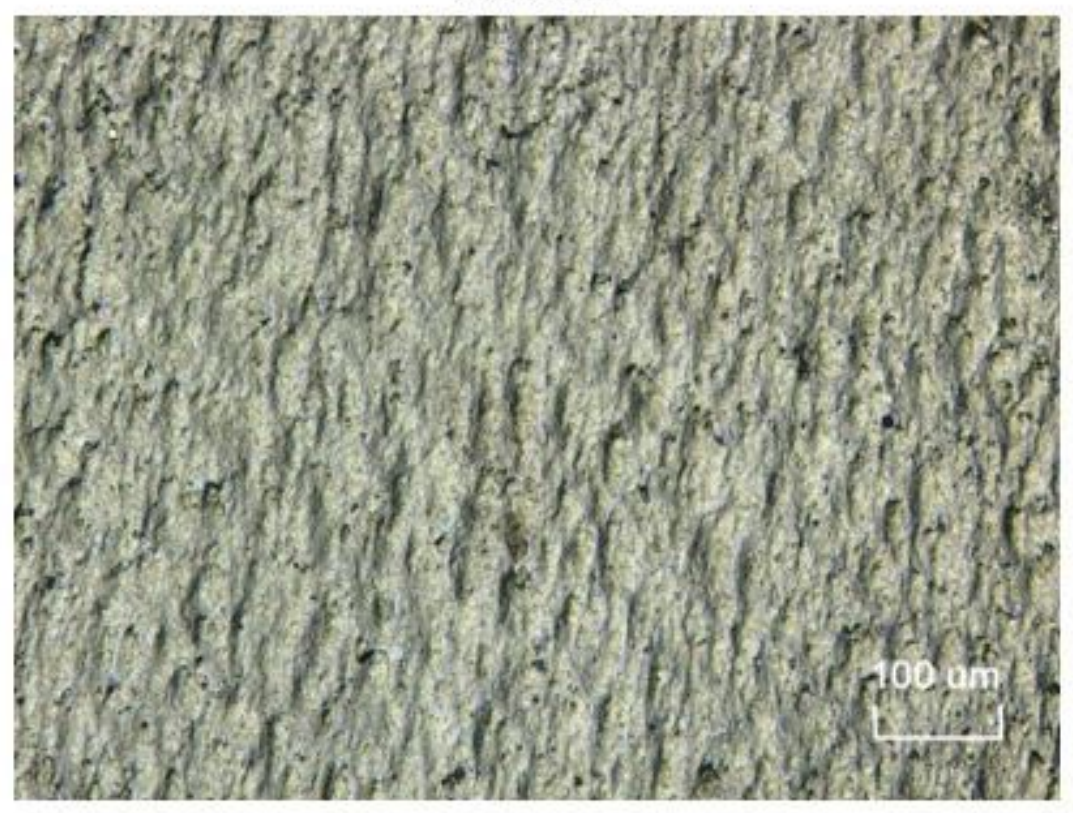

(b) $1.5 \mathrm{~A}$

\section{Figure 9}

The finished surface by MR jet under different current. 


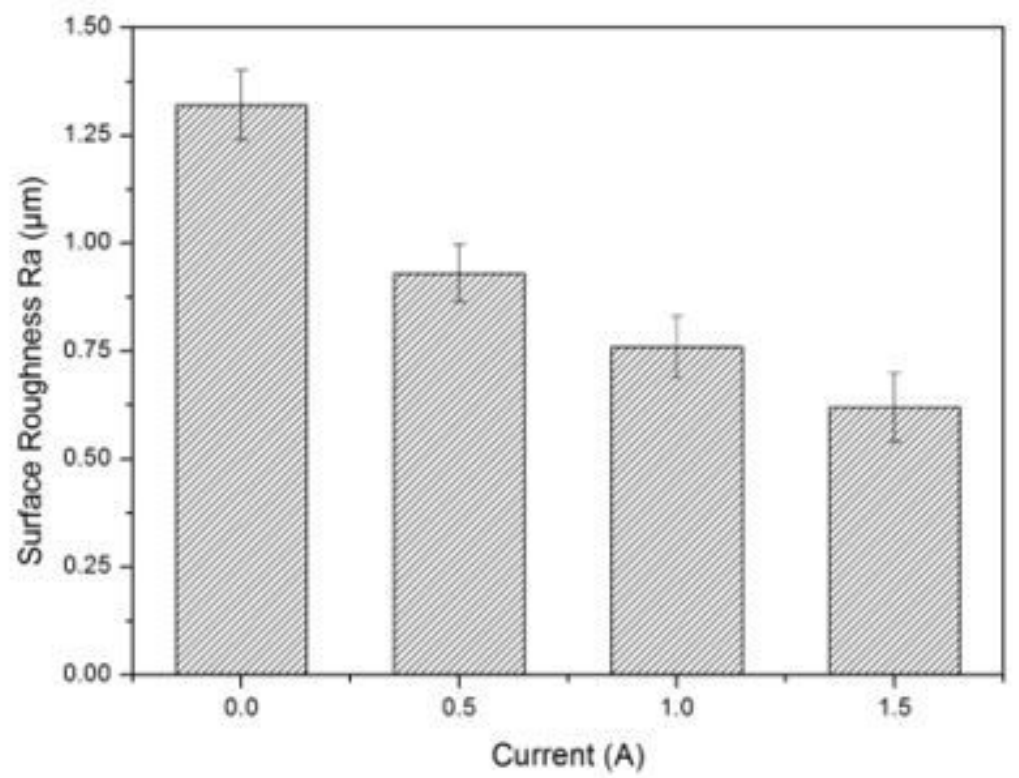

Figure 10

The variation of surface roughness with excitation current. 